\title{
Predictive factors for oocyte retrieval failure in controlled ovarian hyperstimulation protocols: a retrospective observational cohort study
}

\author{
Ayumi Hasegawa, Toshifumi Takahashi", Hideki Igarashi, Mitsuyoshi Amita, Jun Matsukawa and Satoru Nagase
}

\begin{abstract}
Background: Oocyte retrieval failure following an ovarian hyperstimulation protocol is uncommon in assisted reproductive technology (ART) programs. We analyzed the predictive factors for oocyte retrieval failure following controlled ovarian hyperstimulation $(\mathrm{COH})$ with gonadotropin-releasing hormone $(\mathrm{GnRH})$ agonist and $\mathrm{GnRH}$ antagonist protocols in ART programs.

Methods: This study was a retrospective cohort observational study. In total, 744 cycles from 361 patients who underwent controlled ovarian hyperstimulation with GnRH agonist long protocol or antagonist protocol were analyzed. Treatment cycles with oocyte retrieval failure and with one or more oocytes retrieved were compared to determine predictive factors for oocyte retrieval failure using univariate and multilevel multivariate logistic regression analyses.
\end{abstract}

Results: Oocyte retrieval failure occurred in 38 cycles (5.1\%). The oocyte retrieval failure rate of the GnRH antagonist protocol (8.1\%) was significantly higher than that of the GnRH agonist long protocol (3.7\%). On multilevel multivariate logistic analysis, cycles with GnRH antagonist protocol (odds ratio [OR] 3.06, 95 \% confidence interval [CI] 1.05-8.96), estradiol level on the day of human chorionic gonadotropin (hCG) injection (OR 0.997, $95 \%$ Cl 0.996-0.998), and luteinizing hormone $(\mathrm{LH})$ level on the day of $\mathrm{hCG}$ injection (OR 1.19, $95 \% \mathrm{Cl}$ 1.06-1.33) were independent predictive factors for oocyte retrieval failure. The efficacy of estradiol and LH levels on the day of hCG injection for predicting oocyte retrieval failure was evaluated using receiver operating characteristic curves. In all cycles, the areas under the curve (AUCs) for estradiol and LH were 0.84 and 0.63 , respectively, for all cycles; 0.84 and 0.52 , respectively, for cycles with GnRH agonist long protocol; and 0.81 and 0.82, respectively, for cycles with $\mathrm{GnRH}$ antagonist protocol.

Conclusions: Our results suggest that in cycles with GnRH antagonist protocol, the levels of estradiol and LH on the day of hCG injection might be predictive factors for oocyte retrieval failure. This relationship may provide useful information to both patients and physicians for developing better $\mathrm{COH}$ protocols in ART programs.

Keywords: Assisted reproductive technology, Oocyte retrieval, Empty follicle syndrome, Controlled ovarian hyperstimulation, Gonadotropin-releasing hormone agonist, Gonadotropin-releasing hormone antagonist

\section{Background}

Assisted reproductive technology (ART) has been widely used for infertility treatment [1]. Acquisition of oocytes is the first step towards successful outcomes in an ART program. Ovarian hyperstimulation with gonadotropin-

\footnotetext{
* Correspondence: totakaha@med.id.yamagata-u.ac.jp

* Correspondence: totakaha@med.id.yamagata-u.ac.jp
Department of Obstetrics and Gynecology, Yamagata University Faculty of Medicine, Yamagata 990-9585, Japan
}

(C) 2015 Hasegawa et al. This is an Open Access article distributed under the terms of the Creative Commons Attribution License (http://creativecommons.org/licenses/by/4.0), which permits unrestricted use, distribution, and reproduction in any medium, provided the original work is properly credited. The Creative Commons Public Domain Dedication waiver (http:// creativecommons.org/publicdomain/zero/1.0/) applies to the data made available in this article, unless otherwise stated. releasing hormone (GnRH) agonist and GnRH antagonist oocytes [2].

Oocyte retrieval failure, i.e., zero oocytes retrieved following an ovarian hyperstimulation protocol, is uncommon in ART programs [3] and referred to as "empty follicle syndrome" [3, 4]. The incidence of oocyte retrieval failure, involving a minimum ovarian hyperstimulation protocol 
with clomiphene citrate, ranges from $0.045 \%$ to $7 \%$ [3]. It may cause substantial stress and anxiety for both patients and physicians. However, the etiology of oocyte retrieval failure remains unknown.

In the present study, we analyzed the predictive factors for oocyte retrieval failure following controlled ovarian hyperstimulation with GnRH agonist and GnRH antagonist protocols in ART programs.

\section{Methods}

This study was a retrospective cohort observational study. A total of 744 cycles from 361 patients who underwent in vitro fertilization (IVF) and intracytoplasmic sperm injection (ICSI) programs in the period from November 2006 to November 2014 at Yamagata University Hospital, Yamagata, Japan, were analyzed. The Yamagata University Ethical Committee on human subjects approved the present study, and written informed consent was obtained from all patients.

\section{Controlled ovarian hyperstimulation and oocyte retrieval}

All patients underwent controlled ovarian hyperstimulation $(\mathrm{COH})$ by daily injections of human menopausal gonadotropin or recombinant follicle-stimulating hormone (FSH) and pituitary desensitization following a $\mathrm{GnRH}$ agonist long protocol or GnRH antagonist protocol. Cycle monitoring was carried out using transvaginal sonography. In the GnRH agonist long protocol, the patients received a GnRH agonist (Suprecure nasal spray, 600 or $900 \mu \mathrm{g}$ daily, Mochida, Tokyo, Japan) from the mid-luteal phase of the previous cycle to the day of human chorionic gonadotropin (hCG) injection. In the GnRH antagonist protocol, the patients received a GnRH antagonist (Setrotide, $0.25 \mathrm{mg}$ daily, Merck Serono, Tokyo, Japan), which was administered when the leading follicle was 13 to $14 \mathrm{~mm}$ in a diameter or on cycle day 8 and continued until the day of hCG injection. Cumulus oocyte complexes (COCs) were aspirated without flushing $36 \mathrm{~h}$ after hCG injection using an 18- or 19-gauge needle guided by transvaginal ultrasonography. The collected COCs were counted and subsequently inseminated using either conventional IVF or ICSI.

\section{Hormone assays}

Hormone measurements were performed on the day of hCG injection. Hormone concentrations were quantified using commercially available immunoassay kits. Luteinizing hormone (LH), FSH, and prolactin (PRL) were measured using an electrochemiluminescence immunoassay (ECLusys reagent LH, FSH, PRL kit; Roche Diagnostics, Inc., Tokyo, Japan). Estradiol and progesterone levels were measured using a chemiluminescence immunoassay (Architect estradiol and progesterone kit; Abbott Japan, Inc., Tokyo, Japan). Reliability criteria for all assays were established. The interassay coefficient of variation was $3.3 \%$ for estradiol and $7.9 \%$ for progesterone. The intraassay coefficient of variation was $5.2 \%$ for estradiol and $7.2 \%$ for progesterone. All samples were assayed in duplicate.

\section{Statistical analysis}

We compared various possible factors affecting oocyte retrieval between patients with zero oocytes retrieved and those from whom one or more oocytes were retrieved. Data are presented as mean \pm SD if a normal distribution was expected; otherwise, median and range were used. In univariate analysis, differences in nominal variables between the groups were compared using the $X^{2}$ test, unless the expected frequency was $<5$, in which case Fisher's exact probability test was used. Continuous variables were analyzed using nonparametric MannWhitney $U$ test. In the multivariate analysis, multilevel multivariate logistic regression models were used to determine the independent prognostic factors for oocyte retrieval failure. The first level was defined as the cycle and the second level was defined as the patient. This approach permitted analyses at the cycle level while adjusting for within-patient correlations [5]. The area under the receiver operating characteristic (ROC) curve

Table 1 Patient characteristics

\begin{tabular}{|c|c|}
\hline No. of cycles, $n$ & 744 \\
\hline No. of patients, $n$ & 361 \\
\hline Age, years & $37(23-46)^{a}$ \\
\hline Gravida per patient, $n$ & $0(0-7)^{a}$ \\
\hline Parity per patient, $\mathrm{n}$ & $0(0-4)^{a}$ \\
\hline $\mathrm{BMI}, \mathrm{kg} / \mathrm{m}^{2}$ & $21(16-36)^{a}$ \\
\hline Infertility period, years & $6(0-18)^{a}$ \\
\hline Previous treatment cycles, $\mathrm{n}$ & $2(1-16)^{a}$ \\
\hline Cycles with GnRH agonist long/all cycles (\%) & $509 / 744(68.4)$ \\
\hline Cycles with GnRH antagonist/all cycles (\%) & 235/744 (31.6) \\
\hline Duration of $\mathrm{hMG} / \mathrm{rFSH}$, days & $11(7-21)^{\mathrm{a}}$ \\
\hline Dose of hMG/rFSH, IU & $1425(150-4800)^{a}$ \\
\hline \multicolumn{2}{|l|}{ Hormone levels ${ }^{\mathrm{b}}$} \\
\hline $\mathrm{FSH}, \mathrm{mlU} / \mathrm{ml}$ & $13.5(3.2-113.5)^{\mathrm{a}}$ \\
\hline $\mathrm{LH}, \mathrm{mlU} / \mathrm{ml}$ & $2.4(0.1-45.3)^{\mathrm{a}}$ \\
\hline $\mathrm{PRL}, \mathrm{ng} / \mathrm{ml}$ & $30.4(0.6-314)^{\mathrm{a}}$ \\
\hline Estradiol, pg/ml & $1633(62-15,768)^{a}$ \\
\hline Progesterone, ng/ml & $0.75(0.05-10.9)^{\mathrm{a}}$ \\
\hline Endometrial thickness ${ }^{\mathrm{b}}, \mathrm{mm}$ & $10.9(4.6-21.2)^{\mathrm{a}}$ \\
\hline No. of follicles over $15.5 \mathrm{~mm}^{\mathrm{b}}, \mathrm{n}$ & $4(1-16)^{\mathrm{a}}$ \\
\hline
\end{tabular}

${ }^{a}$ Median (range). ${ }^{b}$ Values on the day of hCG injection. BMI: body mass index; GnRH: gonadotropin-releasing hormone; hMG: human menopausal gonadotropin; rFSH: recombinant follicle stimulating hormone; IU: international unit; LH: luteinizing hormone; PRL: prolactin; hCG: human chorionic gonadotropin 
was used to assess the discriminative ability of the logistic models. All statistical analyses were performed using Stata software version 13.1 (Stata Corp LP, College Station, TX, USA). All tests for significance were twotailed, and significance was defined as $p<0.05$.

\section{Results}

The clinical characteristics of the patients are summarized in Table 1. The results of the univariate analyses of cycles with zero oocytes retrieved and cycles with one or more oocytes retrieved are shown in Table 2. Zero oocytes were retrieved in 38 cycles (5.1\% of cycles). The number of patients with zero oocytes retrieved was $34.9 .4 \%$ of patients), because four patients experienced repeated oocyte failure. Both age and parity of the cycles with zero oocytes retrieved were significantly higher than those of the cycles with one or more oocytes retrieved. The rate of oocyte retrieval failure in cycles with $\mathrm{GnRH}$ antagonist protocol (8.1\%) was significantly higher than that in cycles with GnRH agonist long protocol (3.7 \%). Levels of FSH and LH were significantly higher in cycles with zero oocytes retrieved than in those with one or more oocytes retrieved. Levels of PRL, estradiol, and progesterone were significantly lower in cycles with zero oocytes retrieved than in those with one or more oocytes retrieved. The number of follicles over $15.5 \mathrm{~mm}$ on the day of hCG injection was significantly lower in cycles with zero oocytes retrieved than in those with one or more oocytes retrieved.

On multilevel multivariate logistic analysis, GnRH antagonist protocol (odds ratio [OR] 3.06, $95 \%$ confidence interval $[\mathrm{CI}] 1.058 .96, P=0.04)$, estradiol level on the day of hCG injection (OR 0.997, 95 \% CI 0.9960.998, $P=0.001$ ), and LH level on the day of hCG injection (OR 1.19, $95 \%$ CI 1.061.33, $P=0.003$ ) were independent predictive factors for oocyte retrieval failure (Table 3 ). As these parameters appeared important for predicting oocyte retrieval failure, we compared the levels of estradiol and LH in cycles with GnRH agonist long and GnRH antagonist protocols (Fig. 1). Although the median level of estradiol on the day of hCG injection in cycles with zero oocytes retrieved was significantly lower than that in cycles with one or more oocytes retrieved, the median levels of LH on the day of hCG injection did not significantly differ between cycles with zero and one or more oocytes retrieved in cycles with GnRH agonist long protocol (Fig. 1a). By contrast, whereas the level of estradiol on the day of hCG injection in the cycles with zero oocytes retrieved was significantly lower than that in cycles with one more oocytes retrieved, the level of LH on the day of hCG injection in the cycles with zero

Table 2 Univariate analysis of variables in the cycles with one or more oocytes retrieved and zero oocytes retrieved

\begin{tabular}{|c|c|c|c|}
\hline & Oocyte retrieval $(+)$ & Oocyte retrieval $(-)$ & $P$ value \\
\hline No. of cycles/all cycles (\%) & 706/744 (94.9) & $38 / 744(5.1)$ & - \\
\hline Age, years & $37(23-46)^{a}$ & $39(31-46)^{a}$ & 0.01 \\
\hline Gravida per patient, n & $0(0-7)^{\mathrm{a}}$ & $0(0-6)^{a}$ & 0.25 \\
\hline Parity per patient, $\mathrm{n}$ & $0(0-3)^{a}$ & $0(0-4)^{a}$ & 0.02 \\
\hline $\mathrm{BMI}, \mathrm{kg} / \mathrm{m}^{2}$ & $21(16-36)^{a}$ & $21(18-31)^{a}$ & 0.42 \\
\hline Infertility period, years & $6(0-18)^{a}$ & $7(0-16)^{a}$ & 0.09 \\
\hline Previous treatment cycles, $\mathrm{n}$ & $2(1-16)^{a}$ & $2(1-14)^{a}$ & 0.87 \\
\hline $\begin{array}{l}\text { No. of cycles with GnRH } \\
\text { agonist long/no. of cycles (\%) }\end{array}$ & 190/706 (69.4) & $19 / 38(50.0)$ & 0.02 \\
\hline $\begin{array}{l}\text { No. of cycles with GnRH } \\
\text { antagonist/no. of cycles/ (\%) }\end{array}$ & 216/706 (30.6) & $19 / 38(50.0)$ & 0.02 \\
\hline Duration of $\mathrm{hMG} / \mathrm{rFSH}$, days & $11(7-21)^{a}$ & $12(8-20)^{a}$ & 0.49 \\
\hline Dose of hMG/rFSH, IU & $1425(150-4800)^{a}$ & $1500(900-4800)^{a}$ & 0.20 \\
\hline \multicolumn{4}{|l|}{ Hormone levels ${ }^{\mathrm{b}}$} \\
\hline $\mathrm{FSH}, \mathrm{mlU} / \mathrm{ml}$ & $13.4(3.2-113.5)^{\mathrm{a}}$ & $16.8(7.5-43.5)^{\mathrm{a}}$ & $<0.001$ \\
\hline $\mathrm{LH}, \mathrm{mlU} / \mathrm{ml}$ & $2.3(0.1-26.8)^{\mathrm{a}}$ & $3.8(0.1-45.3)^{a}$ & 0.006 \\
\hline PRL, $\mathrm{ng} / \mathrm{ml}$ & $30.7(0.6-314)^{a}$ & $21.3(9.3-56.8)^{\mathrm{a}}$ & $<0.001$ \\
\hline Estradiol, pg/ml & $1717(88-15,768)^{\mathrm{a}}$ & $633(62-1970)^{a}$ & $<0.001$ \\
\hline Progesterone, ng/ml & $0.77(0.05-10.9)^{a}$ & $0.51(0.1-6.48)^{a}$ & 0.02 \\
\hline Endometrial thickness ${ }^{\mathrm{b}}, \mathrm{mm}$ & $10.9(4.6-21.2)^{\mathrm{a}}$ & $10.3(6.2-17.2)^{\mathrm{a}}$ & 0.51 \\
\hline No. of follicles over $15.5 \mathrm{~mm}^{\mathrm{b}}, \mathrm{n}$ & $4(1-16)^{a}$ & $2(1-6)^{a}$ & $<0.001$ \\
\hline
\end{tabular}

${ }^{a}$ Median (range). ${ }^{b}$ Values on the day of hCG injection. BMl: body mass index; GnRH: gonadotropin-releasing hormone; hMG: human menopausal gonadotropin; rFSH: recombinant follicle stimulating hormone; IU: international unit; LH, luteinizing hormone; PRL, prolactin; hCG: human chorionic gonadotropin 
Table 3 Multilevel multivariate logistic analysis for oocyte retrieval failure

\begin{tabular}{llll}
\hline Variables & Odds ratio & $95 \%$ confidence interval & $P$ value \\
\hline $\begin{array}{l}\text { Cycles with GnRH } \\
\text { antagonist protocol }\end{array}$ & 3.06 & $1.05-8.96$ & 0.04 \\
$\begin{array}{l}\text { Estradiol on the day } \\
\text { of hCG injection }\end{array}$ & 0.997 & $0.996-0.998$ & 0.0001 \\
$\begin{array}{l}\text { LH on the day of } \\
\text { hCG injection }\end{array}$ & 1.19 & $1.06-1.33$ & 0.003 \\
\hline
\end{tabular}

GnRH: gonadotropin releasing hormone; hCG: human chorionic gonadotropin; LH: luteinizing hormone

oocytes retrieved was significantly higher than that in the cycles with one or more oocytes retrieved in cycles with GnRH antagonist protocol (Fig. 1b).

Next, we validated the efficacy of the levels of estradiol and LH on the day of hCG injection in predicting the possibility of oocyte retrieval failure. Figure 2 shows the ROCs of estradiol and $\mathrm{LH}$ for the prediction of oocyte retrieval failure. In all cycles, the areas under the curve (AUCs) for estradiol and LH were 0.84 and 0.63 , respectively. In cycles with $\mathrm{GnRH}$ agonist long protocol, the
AUCs for estradiol and $\mathrm{LH}$ were 0.84 and 0.52 , respectively. In cycles with $\mathrm{GnRH}$ antagonist protocol, the AUCs for estradiol and LH were 0.81 and 0.82 , respectively. Table 4 summarizes the sensitivities, specificities, and positive and negative predictive values for predicting oocyte retrieval failure at various thresholds for estradiol and LH levels in all cycles, cycles with GnRH agonist long protocol, and cycles with $\mathrm{GnRH}$ antagonist protocol.

\section{Discussion}

We evaluated the predictive factors for oocyte retrieval failure with controlled ovarian hyperstimulation protocols in ART treatment cycles. The independent predictive factors for oocyte retrieval failure on multilevel multivariate analysis were use of the GnRH antagonist protocol and levels of estradiol and LH on the day of hCG injection. Analyses of ROCs revealed that estradiol level was more predictive of oocyte retrieval failure than LH level on the day of hCG injection in all treatment cycles, whereas estradiol and LH levels demonstrated similar predictive power for oocyte retrieval failure in cycles with $\mathrm{GnRH}$ antagonist protocol.

\section{A GnRH agonist long}
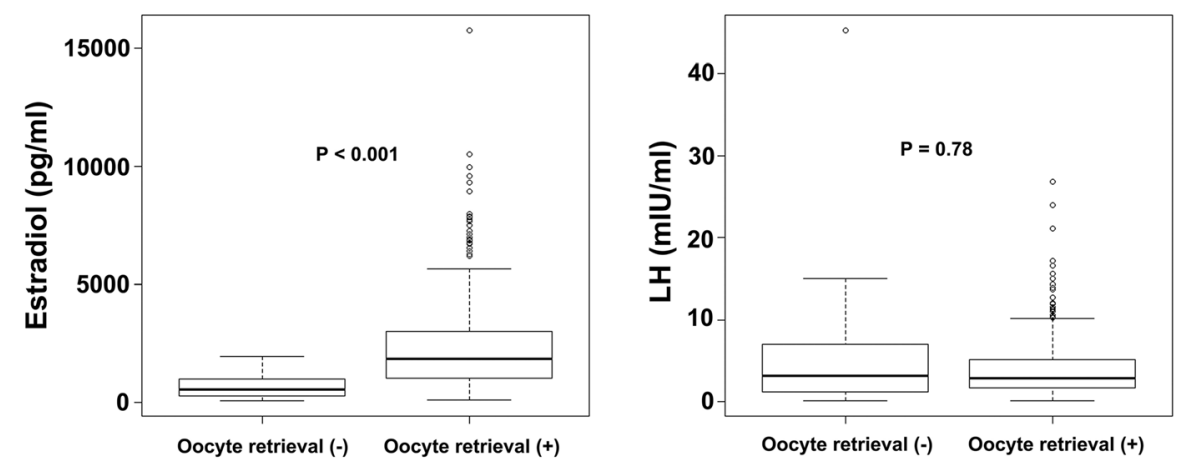

\section{B GnRH antagonist}
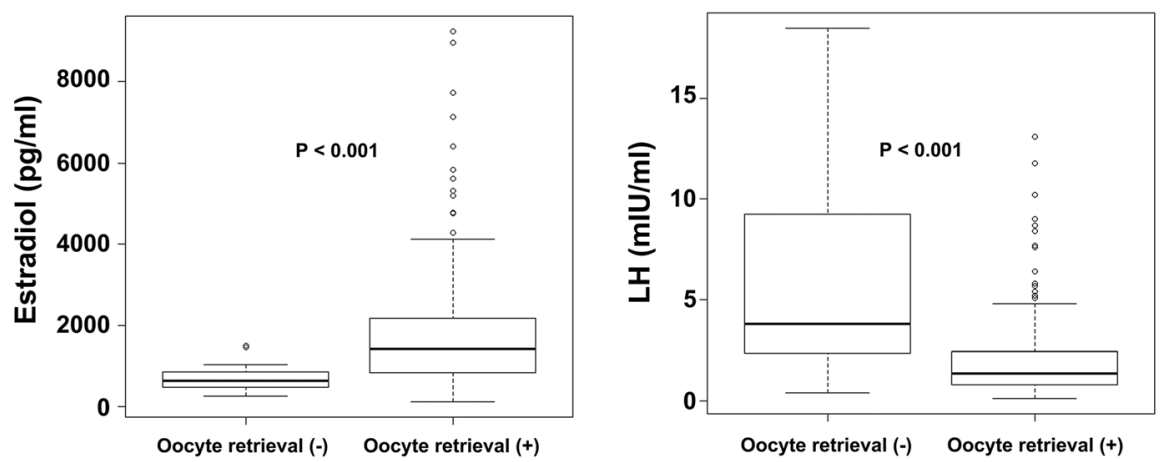

Fig. 1 Levels of estradiol and LH on the day of hCG injection in patients who underwent GnRH agonist long and GnRH antagonist protocols in cycles with zero and one or more oocytes retrieved. a. levels of estradiol and LH on the day of hCG injection in cycles with GnRH agonist long protocol. b. levels of estradiol and LH on the day of hCG injection in cycles with GnRH antagonist protocol 

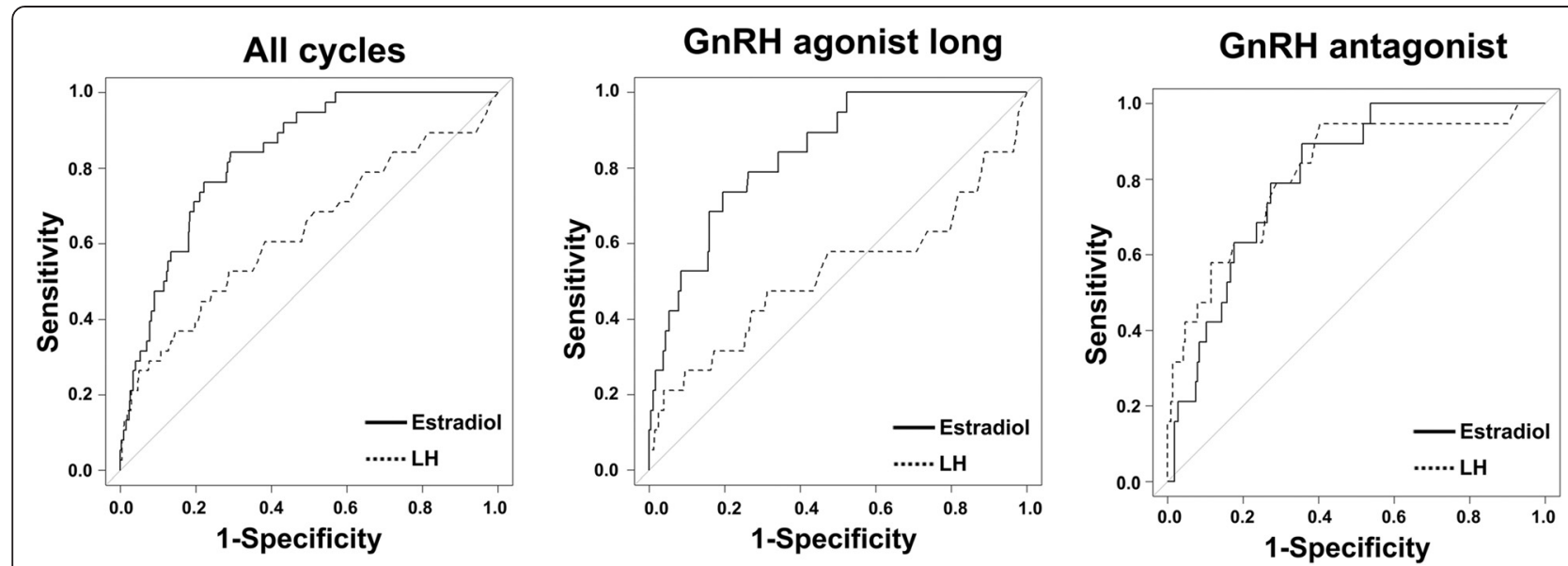

Fig. 2 Receiver operating characteristic (ROC) curves of estradiol and LH on the day of hCG injection. ROC curves of estradiol and LH on the day of hCG injection in the cycles with all, GnRH agonist long, and GnRH antagonist protocols for predicting oocyte retrieval failure

In the present study, we found that the odds ratio of oocyte retrieval failure with the GnRH antagonist protocol was three times that of the GnRH agonist long protocol. There have been no previous studies comparing types of $\mathrm{COH}$ in cycles with oocyte retrieval failure. The number of oocytes retrieved in cycles with $\mathrm{GnRH}$ antagonist protocol tends to lower than that in cycles with GnRH agonist long protocol [6, 7]. The etiology of the higher incidence of oocyte retrieval failure in cycles with GnRH antagonist protocol remains unclear. As the level of LH on the day of hCG injection was significantly higher in cycles with oocyte retrieval failure, insufficient LH suppression in the GnRH antagonist protocol might be a cause of oocyte retrieval failure.

A lower level of estradiol demonstrated positive predictive value for oocyte retrieval failure. Baum et al. reported that lower estradiol level on the day of hCG injection was a risk factor for oocyte retrieval failure in ART treatment cycles with controlled ovarian hyperstimulation protocols [8]. In the present study, the median level of estradiol in cycles with oocyte retrieval failure was three times greater than that in cycles with one or more oocytes retrieved. Previous studies also reported that lower estradiol level on the day of hCG injection was a risk factor for oocyte retrieval failure in ART treatment cycles with $\mathrm{COH}[9$, 10]. The etiology of lower estradiol level on the day of hCG injection might be poor follicle development. In fact, we observed a lower number of developing follicles in cycles with oocyte retrieval failure compared to cycles with one or more oocytes retrieved.

Higher LH level on the day of hCG injection was also a positive predictor for oocyte retrieval failure. Choi et al. reported that the cancellation rate of ART treatment cycles was greater in cases of higher LH levels on the day of hCG injection than in cases of lower LH levels [11]. Premature LH surge results in cancellation of IVF treatment cycles or developmental arrest of oocytes because of early luteinization of immature follicles before oocyte retrieval [12-14]. Taken together, these results suggest that insufficient $\mathrm{LH}$ suppression during $\mathrm{COH}$ and fewer developing follicles might be a cause of oocyte retrieval failure.

Several candidates for the etiology of oocyte retrieval failure in ART treatment cycles have been proposed. First, the low bioavailability of hCG is one possible etiology of oocyte retrieval failure [15-17]. Zegers-Hochschild et al. reported that low bioavailability of hCG may be linked to intrinsic defects in the in vivo biological activity of some batches of hCG [15]. In the present study, the patients

Table 4 Predictive efficacy of estradiol and LH levels on the day of hCG injection for oocyte retrieval failure

\begin{tabular}{|c|c|c|c|c|c|}
\hline Type of $\mathrm{COH}$ & Threshold value & Sensitivity & Specificity & PPV & NPV \\
\hline \multirow[t]{2}{*}{ All cycles } & Estradiol $1080 \mathrm{pg} / \mathrm{ml}$ & 0.71 & 0.84 & 0.19 & 0.98 \\
\hline & LH $3.8 \mathrm{mlU} / \mathrm{ml}$ & 0.71 & 0.53 & 0.07 & 0.97 \\
\hline \multirow[t]{2}{*}{ Cycles with GnRH agonist long } & Estradiol 887 pg/ml & 0.81 & 0.74 & 0.14 & 0.99 \\
\hline & LH $10.9 \mathrm{mlU} / \mathrm{ml}$ & 0.96 & 0.21 & 0.06 & 0.99 \\
\hline \multirow[t]{2}{*}{ Cycles with GnRH antagonist } & Estradiol $1040 \mathrm{pg} / \mathrm{ml}$ & 0.64 & 0.90 & 0.24 & 0.98 \\
\hline & LH $1.7 \mathrm{mlU} / \mathrm{ml}$ & 0.60 & 0.95 & 0.37 & 0.98 \\
\hline
\end{tabular}


received hCG purchased from the same company, whose batches may have differed during the study period. Therefore, problems with the hCG drug might be a cause of oocyte retrieval failure. Reduced follicle development during $\mathrm{COH}$ is another possible etiology of oocyte retrieval failure [18]. Patients with a poor response to $\mathrm{COH}$ are vulnerable to oocyte retrieval failure $[3,7-9,18]$. These patients are considered to have a diminished ovarian reserve mainly due to ovarian aging $[3,9,10]$. In the present study, patient age was significantly higher in cycles with oocyte retrieval failure than those in which one or more oocytes were retrieved. Because we did not measure FSH levels at the early follicular phase or anti-Müllerian hormone, it is possible that patients with oocyte retrieval failure were subject to diminished ovarian reserve. The final possible etiology of oocyte retrieval failure is human error, such as a missed and/or incorrect dose of hCG injection [18-20]. We did not exclude possible cases of oocyte retrieval failure caused by human errors, such as a missed and/or incorrect dose of hCG injection.

When interpreting our results, the strengths and limitations of our study must be considered in light of its retrospective cohort design. There were potential confounding factors that should be acknowledged. In the present study, in univariate analysis, the patients' age and parity were significantly higher in the cycles with zero oocytes retrieved than those of the cycles with one or more oocytes retrieved. To eliminate confounding factors, we applied multilevel multivariate analysis to determine the predictive factors for oocyte retrieval failure. As a result, age and parity were eliminated as candidate predictive factors for oocyte retrieval failure. However, because of its small sample size, the findings of the current study are vulnerable to type II error [21]. A larger-scale study is needed to evaluate the predictive factors for oocyte retrieval failure with $\mathrm{COH}$ in ART treatment cycles.

\section{Conclusions}

Our results suggest that GnRH antagonist protocol, lower level of estradiol, and higher level of LH on the day of hCG injection might be positive predictors for oocyte retrieval failure. These findings provide useful information to both patients and physicians for developing better $\mathrm{COH}$ protocols in ART programs.

\footnotetext{
Abbreviations

AUC: Area under the curve; ART: Assisted reproductive technology; $\mathrm{Cl}$ : Confidence interval; $\mathrm{COC}$ : Cumulus oocyte complex; $\mathrm{COH}$ : Controlled ovarian hyperstimulation; FSH: Follicle stimulating hormone; GnRH: Gonadotropin-releasing hormone; hCG: Human chorionic gonadotropin; ICSI: Intracytoplasmic sperm injection; IVF: In vitro fertilization; LH: Luteinizing hormone; OR: Odds ratio; ROC: Receiver operating characteristic.
}

\section{Competing interests}

The authors declare that they have no competing interests.

\section{Authors' contributions}

$\mathrm{AH}$ and $\Pi$ contributed to study conception and design; acquisition, analysis, and interpretation of data; and drafting of the manuscript. HI, MA, and JM contributed to acquisition and analysis of data. S.N. contributed to drafting of the manuscript and critical discussion. All the authors read and approved the final manuscript.

\section{Acknowledgement}

This study was supported by Grants-in-Aid for General Science Research No. 25462550 to Toshifumi Takahashi and No. 26462474 to Hideki Igarashi.

Received: 15 March 2015 Accepted: 27 May 2015

Published online: 02 June 2015

\section{References}

1. Mansour R, Ishihara O, Adamson GD, Dyer S, de Mouzon J, Nygren KG, et al. International Committee for Monitoring Assisted Reproductive Technologies world report: Assisted Reproductive Technology 2006. Hum Reprod. 2014;29:1536-51

2. Bosch E, Ezcurra D. Individualised controlled ovarian stimulation (iCOS): maximising success rates for assisted reproductive technology patients. Reprod Biol Endocrinol. 2011;9:82.

3. Kim JH, Jee BC. Empty follicle syndrome. Clin Exp Reprod Med. 2012;39:132-7.

4. Coulam CB, Bustillo M, Schulman JD. Empty follicle syndrome. Fertil Steril. 1986;46:1153-5.

5. Tomasi C, Leyland AH, Wennström JL. Factors influencing the outcome of non-surgical periodontal treatment: a multilevel approach. J Clin Periodontol. 2007:34:682-90.

6. Del Gadillo JC, Siebzehnrübl E, Dittrich R, Wildt L, Lang N. Comparison of $\mathrm{GnRH}$ agonists and antagonists in unselected IVF/ICSI patients treated with different controlled ovarian hyperstimulation protocols: a matched study. Eur J Obstet Genecol Reprod Biol. 2002;102:179-83.

7. Moraloglu O, Kilic S, Karayalçin R, Yuksel B, Tasdemir N, Işik A, et al. Comparison of GnRH agonists and antagonists in normoresponder IVF/ICSI in Turkish female patients. Adv Ther. 2008;25:266-73.

8. Baum M, Machtinger R, Yerushalmi GM, Maman E, Seidman DS, Dor J, et al. Recurrence of empty follicle syndrome with stimulated IVF cycles. Gynecol Endocrinol. 2012;28:293-5.

9. Zreik TG, Garcia-Velasco JA, Vergara TM, Arici A, Olive D, Jones EE. Empty follicle syndrome: evidence for recurrence. Hum Reprod. 2000;15:999-1002.

10. Younis JS, Skournik A, Randin O, Haddad S, Bar-Ami S, Ben-Ami M. Poor oocyte retrieval is a manifestation of low ovarian reserve. Fertil Steril. 2005:83:504-7.

11. Choi MH, Cha SH, Park CW, Kim JY, Yang KM, Song IO, et al. The effectiveness of earlier oocyte retrieval in the case of a premature luteinizing hormone surge on hCG day in in vitro fertilization-embryo transfer cycles. Clin Exp Reprod Med. 2013;40:90-4.

12. Stanger JD, Yovich JL. Reduced in-vitro fertilization of human oocytes from patients with raised basal luteinizing hormone levels during the follicular phase. Br J Obstet Gynaecol. 1985;92:385-93.

13. Droesch K, Muasher SJ, Brzyski RG, Jones GS, Simonetti S, Liu HC, et al. Value of suppression with a gonadotropin-releasing hormone agonist prior to gonadotropin stimulation for in vitro fertilization. Fertil Steril. 1989;51:292-7.

14. Cummins JM, Yovich JM, Edirisinghe WR, Yovich JL. Pituitary downregulation using leuprolide for the intensive ovulation management of poor prognosis patients having in vitro fertilization (IVF)-related treatments. J In Vitro Fert Embryo Transf. 1989;6:345-52.

15. Zegers-Hochschild F, Fernandez E, Mackenna A, Fabres C, Altieri E, Lopez T. The empty follicle syndrome: a pharmaceutical industry syndrome. Hum Reprod. 1995;10:2262-5.

16. Ubaldi F, Nagy Z, Janssenwillen C, Smitz J, Van Steirteghem A, Devroey P. Ovulation by repeated human chorionic gonadotrophin in 'empty follicle syndrome' yields a twin clinical pregnancy. Hum Reprod. 1997;12:454-6.

17. Lok F, Pritchard J, Lashen H. Successful treatment of empty follicle syndrome by triggering endogenous LH surge using GnRH agonist in an antagonist down-regulated IVF cycle. Hum Reprod. 2003;18:2079-81.

18. Mesen TB, Yu B, Richter KS, Widra E, DeCherney AH, Segars JH. The prevalence of genuine empty follicle syndrome. Fertil Steril. 2011;96:1375-7. 
19. Meniru Gl, Craft IL. Evidence from a salvaged treatment cycle supports an etiology for the empty follicle syndrome that is related terminal follicular developmental events. Hum Reprod. 1997;2:2385-7.

20. Quintans CJ, Donaldson MJ, Blanco LA, Pasqualini RS. Empty follicle syndrome due to human errors: its occurrence in an in-vitro fertilization programme. Hum Reprod. 1998;3:2703-5.

21. Glantz SA. It is all in the numbers. J Am Coll Cardiol. 1993;21:835-7.

Submit your next manuscript to BioMed Central and take full advantage of:

- Convenient online submission

- Thorough peer review

- No space constraints or color figure charges

- Immediate publication on acceptance

- Inclusion in PubMed, CAS, Scopus and Google Scholar

- Research which is freely available for redistribution 